\title{
Universiteit
}

Leiden

The Netherlands

\section{Manual or machine? A review of the crisis and disaster}

\section{literature}

Kuipers S, Kantorowicz J., M J.

\section{Citation}

Kuipers S, K. J. , M. J. (2019). Manual or machine? A review of the crisis and disaster literature. Risk, Hazards \& Crisis In Public Policy, 10(4), 388-402. doi:10.1002/rhc3.12181

Version: $\quad$ Not Applicable (or Unknown)

License: $\quad$ Leiden University Non-exclusive license

Downloaded from: $\quad$ https://hdl.handle.net/1887/135627

Note: To cite this publication please use the final published version (if applicable). 


\title{
Manual or Machine? A Review of the Crisis and Disaster Literature
}

\author{
Sanneke Kuipers, Jaroslaw Kantorowicz and Jan Mostert
}

This review aims to map the literature on crisis and disasters by means of a machine-read assessment of the scholarly debate in these domains. The software analyzed abstracts of over 1,000 articles of four related crisis and disaster journals-to find out how the software categorizes their content in a set of topics, what the dominant topics of discussion are, how the topics are distributed over the journals, and what profiles the journals de facto have. The review reflects on the advantages and the limits of machine-read classification and analysis vis-à-vis the manual approach. The conclusion offers an agenda for further research and debate.

KEY WORDS: crisis, disaster, meta literature review, automated text analysis, topic modeling

\section{摘要}

本篇综述旨在通过机器阅读, 对与危机和灾害领域相关的学术辩论进行评估, 以了解该领域的 文献信息。机器阅读软件对与危机和灾害相关的四种期刊中的一千多篇文章摘要进行了分析, 以期发现软件如何在一系列主题中对摘要内容进行分类, 主要探讨的主题是什么, 主题在期刊 中的分布方式是什么, 以及期刊事实上的概况是什么。本片综述思考了相比起人工操作, 机器 阅读编码和分析的优势和限制。结论为今后研究和辩论提供了一个议程。

关键词: 危机，灾害，文献综述，自动化文本分析，主题建模

\section{Resumen}

Esta revisión tiene como objetivo mapear la literatura sobre crisis y desastres mediante una evaluación de lectura automática del debate académico en estos dominios. El software analizó resúmenes de más de mil artículos de cuatro revistas relacionadas con crisis y desastres, para descubrir cómo el software clasifica su contenido en un conjunto de temas, cuáles son los temas de discusión dominantes, cómo se distribuyen los temas en las revistas y qué perfiles tienen las revistas de facto. La revisión reflexiona sobre las ventajas y los límites de la codificación y el análisis de lectura mecánica con respecto al enfoque manual. La conclusión ofrece una agenda para futuras investigaciones y debates.

PALABRAS CLAVE: crisis, desastre, revisión de literatura, análisis de texto automatizado, modelado de temas 


\section{Introduction}

Can humans generate a better overview of scholarly debates than machines? After publishing two meta-reviews based on manual coding of the scholarly literature in Risk, Hazards and Crisis in Public Policy, one on crisis and disaster research (Kuipers \& Welsh, 2017) and one on risk research (Kuipers, van Grieken, \& van Asselt, 2018), time has come for a machine-read assessment of the scholarly debate in these domains.

In this article, we aim to map the literature by feeding the machine with articles' abstracts - to find out how the software categorizes over one thousand articles $(1,044)$ of four-related crisis and disaster journals in a set of topics, what the dominant topics of discussion are, how the topics are distributed over the journals, and what profiles the journals de facto have. We will reflect on the advantages and the limits of machine-read coding and analysis vis-à-vis the manual approach: categories constructed based on expertise and subsequent human coding and interpretation.

We find that the advantage of machine-read assessment is that it offers an unbiased, reliable coding and computation of which concepts, in which combinations, feature predominantly in which journals. By contrast, the advantage of human coding is that it can also identify which topics seem empirically important but are currently under-addressed in scholarly debates. Also, experts can appreciate word combinations better than machines can: words such as crisis, policy, and change may feature too commonly on their own, but in combination, they reveal a specific research orientation. Inter-coder reliability remains high when manually assessing the attention per article for a particular crisis and disaster types. Manual coding on themes proves more difficult in terms of consistent coder agreement.

The results of the machine-read assessment bring us one step further, as it shows us precisely where the interests of crisis and disaster scholars overlap and what topics the scholarly communities cover. In addition, the manual coding revealed possible categories of crisis and disaster types that the machine would not identify and therefore overlook. Manual coding could offer similar advantages in categorizing themes of interest. In the next study train the model to capture also the results for man-made thematic categories, and for disaster and crisis types.

We define disaster as "an episodic event that is collectively construed as very harmful"' (Boin, 't Hart, \& Kuipers, 2017, p. 24; Perry \& Quarantelli, 2005), typically to physical human well-being or to property and infrastructure. In spite of increased interest in so-called man-made disasters (cf. Turner \& Pidgeon, 1997), disaster research predominantly focuses on "natural" agents of destruction with for instance a meteorological (hurricanes and tornadoes), seismological (tsunamis and earthquakes), or geological (landslides) hazard as a trigger (Van Wassenhove, 2006, p. 476; Stallings, 2005). The recognition that most disastrous consequences of natural hazards are in fact human-induced, makes the label "natural disasters" debatable. Scholarly work on disasters usually pertains to long time frames (including the prevention and mitigation stages, and the long-term recovery and health effects) and large groups (communities and populations). 
Crisis research focuses on a narrower time frame "where intervention can still limit the effects of an emerging or escalating incident" (Boin et al., 2017, p. 24). The prospect of a disaster with harmful physical consequences, or a violation of core values of the social system, is imminent and an urgent response is of the essence. Crises encompass more than the threat of physical harm, they also include threats to core values. In addition, crisis research implies that crises can be managed-hence the consistent emphasis on crisis management-if only "people, communities, institutions, leaders or systems [would] rise to the challenge" (Boin et al., 2017, p. 25). Crisis research looks into efforts aimed at minimizing the impact of urgent threats, usually in concertation, at various levels of governance.

Much overlap exists in research and findings: all disasters include phases, where human intervention is crucial and focus on a limited number of responsible actors and organizations, makes sense. In addition, most crises result from a long incubation period and affect large groups of people in the aftermath. Therefore, a selection of both crisis and disaster journals serves to find where common areas of interest emerge, what topics are covered jointly and separately, and to what extent.

The analysis will include the results of the codification of four independent specialized academic journals in the crisis and disaster field. The journals selected for this review were Risk, Hazards and Crisis in Public Policy (RHCPP, 187 articles in 10 volumes, between its starting year 2010 and 2018), the Journal of Contingencies and Crisis Management (JCCM, 234 articles in the past decade, volumes 18-26), the International Journal of Mass Emergencies and Disasters (IJMED, 146 articles since 2010, volumes 28-36), and Disasters (477 articles, volumes 34-42). These journals were chosen not only for their content on crises and disasters but also because the Web of Science provides an uninterrupted sequence of volumes with all articles and all abstracts for each issue in each volume. In order to produce a reliable machine-read analysis, we need equal access to each journal as a source of data. In the following sections, we will first outline the methods of data collection and analysis and subsequently, discuss the results and findings.

The primary method of analysis applied in this paper is an automated quantitative content (text) analysis performed on all the abstracts of all articles of four journals identified in the crisis management literature (RHCPP, JCCM, IJMED, and Disasters) in the period 2010-18. Three distinctive methods of automated text analysis were employed to capture journals' profiles. Our first inquiry aimed to discern the substantive topics that got published in these journals, performing the Latent Dirichlet Allocation (LDA) method (Blei, Ng, \& Jordan, 2003). The second method employed in this article is a keyness analysis or a keyword analysis. This method is widely used in discourse analysis (see, for instance, Gabrielatos, 2018). The overarching idea behind the keyness analysis is to extract terms, which occur with unusual frequency in one journal as compared with another journal. Lastly, to further investigate the similarity of the four journal profiles, we applied several text similarity measures, such as Jaccard and cosine metrics. We based the manual coding, in line with previous meta-reviews, on counting the frequency of key terms within the article titles of each journal in the selected period. We took the same list of codes we used in a previous mapping effort (Kuipers \& Welsh, 2017), to build on 
earlier findings. In ANNEX 1, our methodological considerations are presented in more detail. In the next section, we will discuss the results of the automated text analysis.

\section{Results: Profiles per Journal}

We have identified the top 25 words that journal articles use, and also discerned the themes that are particular for each of the journals through a so-called keyness analysis. Though the journals show some overlap in thematic orientation, they also reveal distinct profiles. Table 1 provides an overview of the top 25 in terms of word frequency per journal, the words per journal that surfaced in the keyness analysis and the topics covered the most per journal.

The RHCPP journal focuses on security and safety risks, disaster hazards, and crises from a governance perspective. The journal distinguishes itself from other crisis and disaster journals by its explicit orientation on crisis and disaster mitigation, preparedness, response, and recovery questions. RHCPP's mission is to contribute to a better understanding of risk, crisis and disaster policies, their evidence base and their effects.

In our analysis, we used different metrics to compute the similarity between the journals, the Jaccard distance, and Cosine distance. Our computation resulted in a cluster analysis that showed that RHCPP and IJMED were most similar in their content, followed by the journal Disasters and then JCCM at much more distance.

IJMED focuses more than RHCPP and the other journals on behavior during and after disasters, on topics such as warning, evacuation, and recovery. It shares an interest in recovery and mitigation with RHCPP and the journal Disasters but shows a more specific orientation toward emergency response and communication in crises, disasters, and emergencies toward citizens, residents, and communities.

Disasters is the journal that not only discusses disasters and their effects on recovery and victims in general but also that shows a special orientation toward disaster risk reduction in the developing countries and a particular focus on humanitarian intervention, aid, and relief also in conflict areas.

The JCCM shares an interest in crisis and risk governance and public organizations with RHCPP, an interest in emergency response with both RHCPP and IJMED and a particular focus on crisis communication with IJMED only. JCCM stands out in its focus on system complexity, organizational safety, and incident management in high-reliability organizations.

\section{Topics Identified in the Total Dataset}

The machine-read analysis served also to identify specific topics (clusters of words that were used in combination in a significant number of abstracts). The authors labeled the topics based on expertise and on reviewing the articles that lay beneath. Table 2 presents the topics including 10 words that represent each cluster 
Kuipers/Kantorowicz/Mostert: Manual or Machine? A Review of the Crisis and Disaster Literature 5

Table 1. Top 25 Words Used, Results of the Keyness Analysis, and Top Five of Topics per Journal

\begin{tabular}{|c|c|c|c|c|}
\hline & RHCPP & JCCM & IJMED & Disasters \\
\hline Top 25 words & $\begin{array}{c}\text { disaster } \\
\text { risk } \\
\text { policy/ies } \\
\text { manag* } \\
\text { govern* } \\
\text { chang* } \\
\text { public } \\
\text { climate } \\
\text { emergency } \\
\text { community } \\
\text { respons* } \\
\text { organ* } \\
\text { social } \\
\text { local } \\
\text { hazard } \\
\text { nuclear } \\
\text { develop* } \\
\text { polit* } \\
\text { nation* } \\
\text { plan* } \\
\text { provid* } \\
\text { system } \\
\text { need } \\
\text { process } \\
\text { recovery }\end{array}$ & $\begin{array}{c}\text { crisis } \\
\text { manag* } \\
\text { response } \\
\text { organ* } \\
\text { communic* } \\
\text { emergency } \\
\text { inform* } \\
\text { disaster } \\
\text { system } \\
\text { public } \\
\text { risk } \\
\text { crises } \\
\text { develop } \\
\text { social } \\
\text { organiz* } \\
\text { media } \\
\text { situat* } \\
\text { resilien* } \\
\text { operat* } \\
\text { plan* } \\
\text { process } \\
\text { event } \\
\text { provid* } \\
\text { need } \\
\text { expert }\end{array}$ & $\begin{array}{c}\text { disaster } \\
\text { community } \\
\text { recover* } \\
\text { social } \\
\text { emergency } \\
\text { risk } \\
\text { evacuat* } \\
\text { manag* } \\
\text { response } \\
\text { plan } \\
\text { impact } \\
\text { inform } \\
\text { local } \\
\text { develop } \\
\text { hurricane } \\
\text { provid* } \\
\text { process } \\
\text { event } \\
\text { need } \\
\text { vulnerab* } \\
\text { prepared } \\
\text { resilien* } \\
\text { govern } \\
\text { hazard } \\
\text { earthquake }\end{array}$ & $\begin{array}{c}\text { disaster } \\
\text { humanitarian } \\
\text { risk } \\
\text { respons } \\
\text { community } \\
\text { manag* } \\
\text { social } \\
\text { develop } \\
\text { emerg* } \\
\text { recover* } \\
\text { organis* } \\
\text { earthquake } \\
\text { vulnerab* } \\
\text { inform } \\
\text { local } \\
\text { flood } \\
\text { health } \\
\text { state } \\
\text { govern } \\
\text { need } \\
\text { provid* } \\
\text { impact } \\
\text { natur* } \\
\text { system } \\
\text { process }\end{array}$ \\
\hline Keyness & $\begin{array}{l}\text { policy } \\
\text { nuclear } \\
\text { climate } \\
\text { change } \\
\text { waste } \\
\text { govern } \\
\text { risk } \\
\text { dispose/al } \\
\text { global } \\
\text { program }\end{array}$ & $\begin{array}{c}\text { crisis } \\
\text { organ* } \\
\text { communic* } \\
\text { organiz* } \\
\text { crises } \\
\text { manage } \\
\text { reliab* } \\
\text { EU } \\
\text { situat* } \\
\text { message }\end{array}$ & $\begin{array}{c}\text { warn } \\
\text { recover* } \\
\text { evacu* } \\
\text { behavior } \\
\text { disaster } \\
\text { hurricane } \\
\text { tornado } \\
\text { community } \\
\text { homeowner } \\
\text { ecosystem }\end{array}$ & $\begin{array}{l}\text { humanitarian } \\
\text { organis* } \\
\text { program } \\
\text { earthquake } \\
\text { displace } \\
\text { livelihood } \\
\text { intervention } \\
\text { aid } \\
\text { conflict } \\
\text { gender }\end{array}$ \\
\hline Topics top 5 & $\begin{array}{l}\text { - Crisis } \\
\text { governance } \\
\text { - Emergency } \\
\text { response } \\
\text { - Public safety } \\
\text { - Recovery } \\
\text { - Risk reduction }\end{array}$ & $\begin{array}{l}\text { - Crisis } \\
\text { communication } \\
\text { - Incident mgt } \\
\text { - Emergency } \\
\text { response } \\
\text { - Crisis governance } \\
\text { - Recovery }\end{array}$ & $\begin{array}{l}\text { - Recovery } \\
\text { - Disaster impact } \\
\text { - Risk reduction } \\
\text { - Crisis communication } \\
\text { - Disaster victims / } \\
\text { emergency response }\end{array}$ & $\begin{array}{l}\text { - Humanitarian } \\
\text { crisis } \\
\text { - Recovery } \\
\text { - Disaster victims } \\
\text { - Risk reduction } \\
\text { - Disaster impact }\end{array}$ \\
\hline
\end{tabular}

and the label we attributed. In the analysis, attempts of totaling 10, 12, 15, or 20 topics have been all tried but a list of 10 topics/clusters proved to result in the best discernable and clearly identifiable variation of topics. With 10 topics in total, the least overlap and most clarity in relation to the research field could be established.

Some topics and their labels may speak for themselves more than others. Topic one, disaster impact, clusters words that pertain to a-potential—impact area, hence 
Table 2. The 10 Substantive Topics Derived From the Automated Text Analysis

\begin{tabular}{|c|c|c|c|c|}
\hline $\begin{array}{l}\text { 1. Disaster } \\
\text { Impact }\end{array}$ & $\begin{array}{l}\text { 2. Humanitarian } \\
\text { Crisis }\end{array}$ & $\begin{array}{l}\text { 3. Incident } \\
\mathrm{Mgt}\end{array}$ & $\begin{array}{l}\text { 4. Emergency } \\
\text { Response }\end{array}$ & $\begin{array}{l}\text { 5. Risk } \\
\text { Reduction }\end{array}$ \\
\hline $\begin{array}{l}\text { evacuation } \\
\text { hurricane } \\
\text { area } \\
\text { resid }^{*} \\
\text { hous }^{*} \\
\text { communit* }^{*} \text { popul* } \\
\text { plan* } \\
\text { impact } \\
\text { katrina }\end{array}$ & $\begin{array}{c}\text { humanitarian } \\
\text { organis* } \\
\text { intern* } \\
\text { aid } \\
\text { relief } \\
\text { govern } \\
\text { conflict } \\
\text { develop } \\
\text { countr* } \\
\text { actor }\end{array}$ & $\begin{array}{c}\text { system } \\
\text { inform } \\
\text { manag* } \\
\text { emerg* } \\
\text { response } \\
\text { decision-mak* } \\
\text { oper* } \\
\text { high } \\
\text { incid* } \\
\text { need }\end{array}$ & $\begin{array}{l}\text { manag* } \\
\text { emerg* } \\
\text { disast* } \\
\text { plan } \\
\text { response } \\
\text { govern } \\
\text { local } \\
\text { prepared } \\
\text { network } \\
\text { collabor* }\end{array}$ & $\begin{array}{c}\text { risk } \\
\text { vulner }^{*} \\
\text { hazard } \\
\text { flood } \\
\text { disast* }^{*} \\
\text { percept* }^{*} \\
\text { communit* }^{*} \\
\text { reduct* } \\
\text { local } \\
\text { strateg* }\end{array}$ \\
\hline $\begin{array}{l}\text { 6. Disaster } \\
\text { Victim }\end{array}$ & $\begin{array}{l}\text { 7. Public } \\
\text { Safety }\end{array}$ & 8. Recovery & $\begin{array}{c}\text { 9. Crisis } \\
\text { Communication }\end{array}$ & $\begin{array}{c}\text { 10. Crisis } \\
\text { Governance }\end{array}$ \\
\hline $\begin{array}{l}\text { health } \\
\text { impact } \\
\text { earthquake } \\
\text { children } \\
\text { women } \\
\text { program* } \\
\text { displac* } \\
\text { gender } \\
\text { livelihood } \\
\text { resourc* }\end{array}$ & $\begin{array}{l}\text { public } \\
\text { nuclear } \\
\text { risk } \\
\text { percept* }^{*} \\
\text { stakehold* } \\
\text { frame } \\
\text { protect } \\
\text { safety } \\
\text { issue } \\
\text { health }\end{array}$ & $\begin{array}{l}\text { disast }^{*} \\
\text { recover* } \\
\text { social } \\
\text { resili }^{*} \\
\text { communit* }^{*} \text { natur* }^{*} \\
\text { post-disast* } \\
\text { respons* } \\
\text { earthquake } \\
\text { process }\end{array}$ & $\begin{array}{l}\text { crisis } \\
\text { communic }^{*} \\
\text { organ* }^{*} \\
\text { inform* } \\
\text { media } \\
\text { respons* } \\
\text { social } \\
\text { crises } \\
\text { manag* } \\
\text { public }\end{array}$ & $\begin{array}{l}\text { change } \\
\text { policy } \\
\text { climate } \\
\text { polit* } \\
\text { secur* } \\
\text { state } \\
\text { institut* } \\
\text { adapt } \\
\text { event } \\
\text { govern }\end{array}$ \\
\hline
\end{tabular}

the words referring to housing, evacuation, residents, communities, and populations. The words relate to physical spaces and groups, which is why the label "disaster impact" comes to mind rather than crisis, which could also relate to more immaterial threats and values. Topic two, humanitarian crisis refers to all forms of humanitarian aid, intervention, and relief in crisis situations that usually find their origin in armed conflict. Topic three perhaps has the most loosely related label. We called the cluster "incident management" because the words seem to indicate those articles that discuss emergencies, incidents, and operations in the context of complex systems. High-reliability theory, normal accidents theory, and other organizational accounts for safe operations fall under this category.

Topic four bundles the words that have to do with emergency response, to manage and govern the immediate activation and work by emergency services in collaborative networks to cope with disaster, and the planning and preparation to do so effectively. Topic five is all about the reduction or mitigation of disaster risk, in particular in relation to natural hazards. Topic six collects words that refer to human victims of a disaster such as the health impact on women and children, or disaster effects on livelihood, loss of resources, and community displacement. Topic seven deals with safety considerations in the public domain, risk perception of particular hazards such as nuclear radiation, and for instance frameworks and programs for health protection. 
The aftermath of crises and disasters is discussed in topic eight: recoveries, resilience, and the social capital that gives rise to such processes in the wake of destruction induced by natural hazards. Topic nine pertains to different forms of crisis communications, the tools (social media), and information processes as an essential part of crisis management. Lastly, topic 10 pertains to policy change and political-institutional response and adaptation to extreme events and to global creeping crises such as climate change.

The topics do not feature equally in the total corpus of articles analyzed. Recovery tops the list, followed by crisis communication as a second, and humanitarian crisis and emergency response sharing the third place. Overall we can see a balanced distribution of topics varying around 10 percent, with the exception of public safety (the least frequently emerging topic of the list, with 5.5 percent and recovery as the most popular with 14.3 percent). Figure 1 presents the distribution when articles can only be exclusively categorized to a single topic, and Figure 2 presents the results when articles can belong to several topics. If we calculate percentages for each topic based on non-exclusive coding (i.e., each article can "belong to" several topics) we obviously end up with more moderate results than Figure 1, with variation being reduced to a range between 7 percent (public safety, lowest) and 12.3 percent (recovery, highest).

Not surprisingly, the journals feature different topics. The section on profiles per journal already briefly discussed the distinction and overlap. Figure 2 visualizes the topic distribution for exclusive coding (the more extreme results), and in the text, we will discuss also the more moderated results of the non-exclusive categorization.

Again, if we allow the software to attribute more than one topic to each article (i.e., non-exclusive coding), this would moderate our results. For instance, the

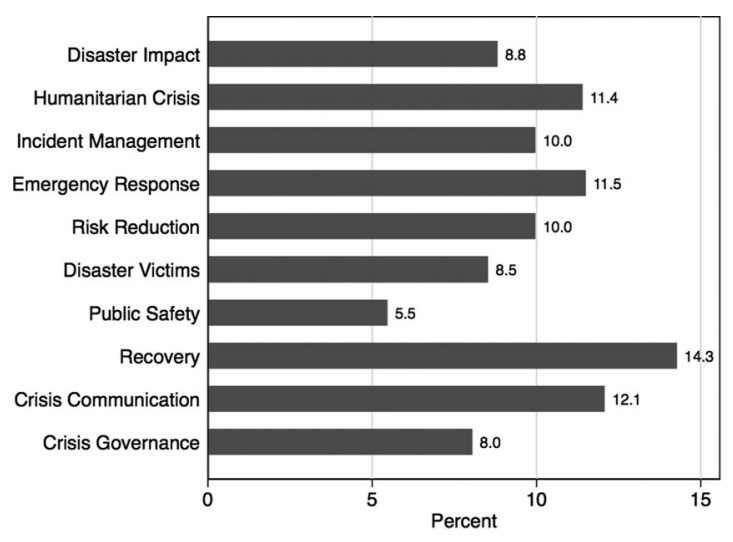

Figure 1. Topic Distribution (Total Dataset, Exclusive Coding). 

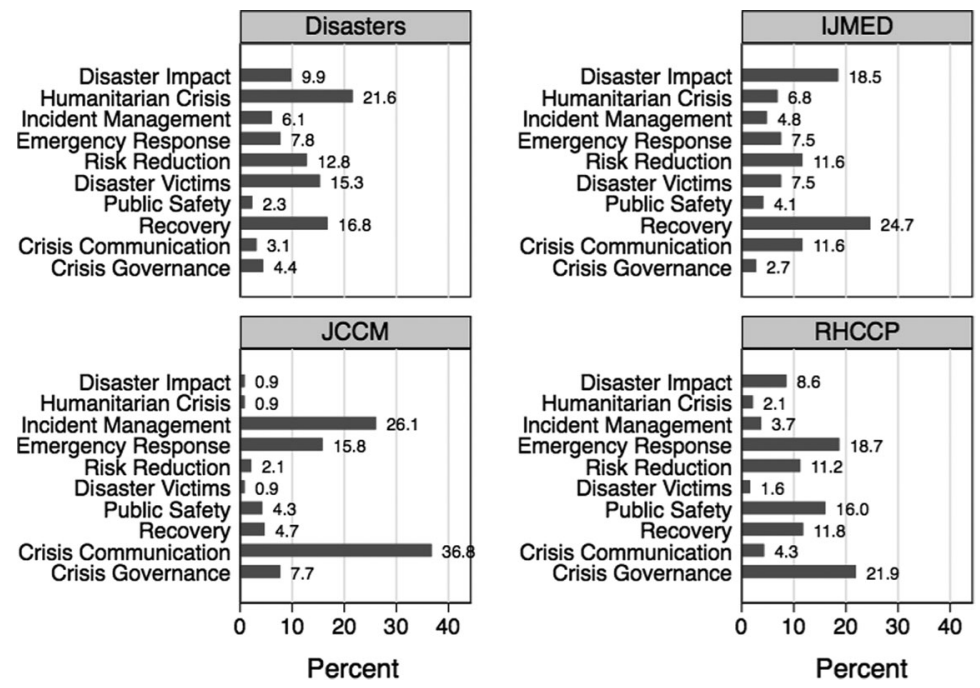

Figure 2. Topic Distribution per Journal (Exclusive Coding).

variation within the journal Disasters would range from 4.3 percent to 16.8 percent (instead of the 2.7-21.6 percent above). With regard to JCCM, Crisis communication would remain the dominant topic, but now at 27 percent instead of 36.8 (results available upon request). The exclusive versus the non-exclusive results in the previous section indicate that even though the exclusive distribution, of course, gives a more extreme outcome, the distribution of the topic in relation to each other remains more or less the same.

\section{Reflection on Topics vis-à-vis Manual Coding}

The fact that the same topics prevail, in roughly the same proportions, whether only one topic can be assigned to an article or several is an important finding because it pertains to the struggle that we had with manual coding. In earlier mapping and review exercises we coded non-exclusively, which resulted in high intercoder reliability between the coders (Kuipers \& Welsh, 2017; Kuipers et al., 2018). After all, when in doubt, several topics could be coded for a single article, and the coder agreement was high as a result.

Prior to computing the machine read results for this review, the authors also attempted to code all articles of the four journals manually. We decided on exclusive coding in order to allow for better regression analysis. As a consequence, the intercoder reliability dropped to a Cohen's $\kappa$ of 0.58 (on average for four journals) for coding each article title under one of 10 previously identified themes. We decided to drop the idea of regression analysis eventually because the coder reliability seemed to be as good as guessing. 
The results for manual coding of crisis types gave much more reason for optimism. We identified 10 crisis types based on a previous inductive review of the literature (we took the same list and the same subcodes as Kuipers \& Welsh 2017, see ANNEX 2). The Cohen's $\kappa$ for intercoder reliability on coding crisis types was much higher than coding on themes ( 0.98 on average for four journals). The increase may result from the fact that many articles discuss one particular crisis type only (either disease, or natural hazard, or industrial accident), where more doubt often exists between thematic approaches, which are also more difficult to discern.

The advantage of manual coding is that it allows the researcher to code instances, situation, and events with a specific name (hurricanes Sandy, Andrew, or Irma; diseases like SARS or influenza; references such as 911 or Fukushima) and identify them as a specific category because humans can interpret where machines can only learn. Also, with a pre-defined list of possible crisis themes and types, human coders can identify gaps in the literature where machines are primarily good at finding frequencies and not at detecting a lack thereof. Human coders can easily discern between supra-categories (themes or types) per case and identify the appropriate code by combining words or by deriving meaning from their context.

On the basis of manual coding, we arrived at the following distribution of crisis and disaster types per journal, visualized in Figure 3. The figures again show that IJMED and Disasters focus predominantly on natural hazards and nature-induced disasters (with near 77 percent and near 54 percent, respectively). The journal Disaster also includes up to 2 percent of articles on humanitarian crises and conflicts. RHCPP and JCCM show much more variety in crisis types discussed. Surprising is the lack of attention for cyber-related crises across the board. The independently generated results of the manual coding are very much in line with the substantive topics and their distribution per journal derived from the automated text analysis.
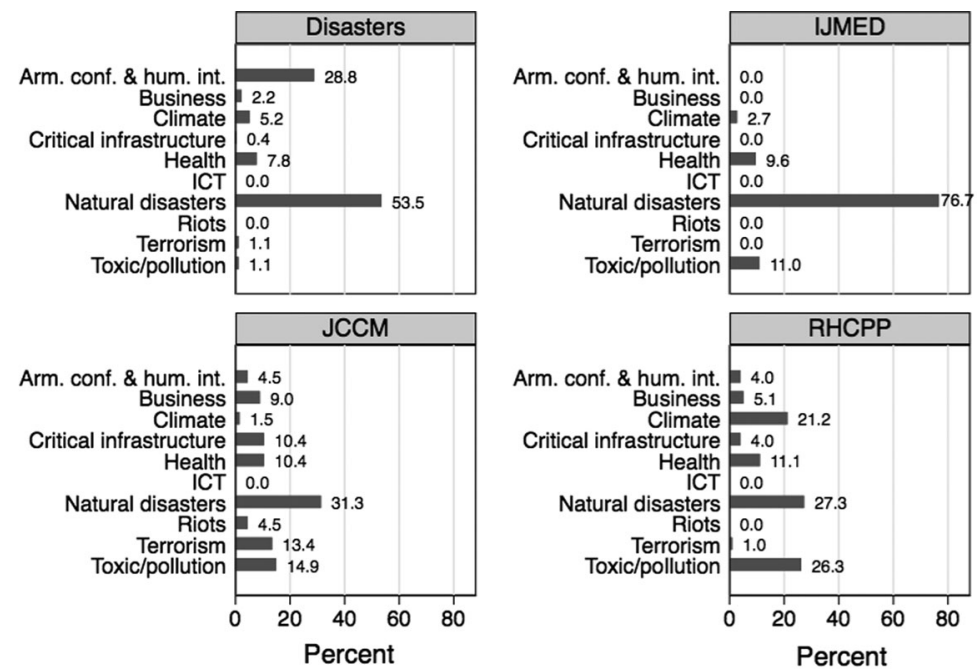

Figure 3. Crisis and Disaster Types per Journal (Manual Coding). 
Table 3. Crisis Types Based on Manual Coding

\begin{tabular}{lccccc}
\hline Crisis Type & RHCPP (\%) & IJMED (\%) & JCCM (\%) & Disasters (\%) & $\begin{array}{c}\text { Total } \\
\text { Average }(\%)\end{array}$ \\
\hline $\begin{array}{l}\text { Armed conflict and } \\
\quad \text { humanitarian intervention }\end{array}$ & 2.2 & 0 & 1.2 & 20 & 9 \\
Business & 2.8 & 0 & 2.5 & 1.5 & 2 \\
Climate & 11.7 & 1.3 & 0.4 & 3.6 & 4 \\
Critical infrastructure & 2.2 & 0 & 2.9 & 0.3 & 1 \\
Health & 6.1 & 4.6 & 2.9 & 5.4 & 5 \\
ICT & 0 & 0 & 0 & 0 & 0 \\
Nature-induced disasters & 15 & 36.6 & 8.8 & 37.2 & 26 \\
Riots & 0 & 0 & 1.3 & 0 & 0 \\
Terrorism & 0.6 & 0 & 3.8 & 0.8 & 1 \\
Toxic/pollution & 14.4 & 5.2 & 4.2 & 0.8 & 5 \\
N/A & 45 & 52.3 & 72 & 30.5 & 47 \\
\hline
\end{tabular}

For on average 47 percent of the articles, we could not identify and code a topic in our manual coding (see category N/A in Table 3). In Table 3, the percentages per journal are listed when we take the share of articles into account that does not discuss a specific crisis or disaster type. The percentages indicate that the journal Disasters is for instance much more case-oriented than the JCCM. Such a conclusion would be more difficult to draw from automated text analysis.

A next step and plan for further research would be to teach the machine to code the types (as well as possible, also including the specific instances and names) so that we could combine the results on the topics with the results on the types. Now, we only know per journal the main topics and the main crisis types, but not which combinations appear most frequently and which do not. The lack of attention for particular crisis types is a highly informative result from the manual coding effort and provides added value vis-à-vis machine coding.

\section{Agenda and Road Ahead}

The trial between man and machine does not produce a clear winner in terms of the best overview of the dominant topics and types discussed in the crisis and disaster literature. Yet it triggers a few questions for further study. The ambition to employ the machine to code specific categories of scholarly interest such as the crisis types is only one possible next step, which should definitely be followed by regression analysis on combinations between topics and types. Do studies on recovery mainly focus on natural hazards, or also on industrial accidents and social unrest? Does research on emergency response also focus on large-scale disaster, or rather on more frequent recurring emergencies such as routine fires and accidents? What combinations would be logical and yet unaddressed?

The current machine coding project also sparked our interest in a more elaborate bibliometric analysis. Where do researchers come from? Which pockets of 
expertise exist in our field worldwide? What do they focus on? Whom do they cite? What does that tell us? Another scholarly project lies ahead.

The more crisis-oriented journals (JCCM and RHCPP) have a joint interest in governance issues, the organization of emergency response, and recovery efforts. They combine this with a dominance of empirical research on not only natureinduced disasters but also on public health crises, critical infrastructure collapses, corporate crises, terrorist attacks, and toxic spills and pollution. These latter types scarcely get attention in the disaster-oriented journals, which predominantly focus on natural hazards and the damage they cause.

The main distribution of topics and overlap between the journals can be visualized as follows (Figure 4). The journal IJMED shares all its topics with at least one other journal. RHCPP (public safety), JCCM (incident management), and Disasters (Humanitarian crises) each have one dominant outlier, though the topics distribution in Figure 2 reveals that all journals cover all topics at least to some extent. JCCM and Disasters have least in common, in terms of focus.

This article tells us about the distinct characteristics and profiles of the journals and as such informs readers on where to look for specific debates. In an era where machine-driven online publications dominate the scholarly landscape, each article is increasingly a stand-alone product doing its own online marketing and inviting its own readership and citations. Journals can make a difference again by showing the coherence between their contributions through their distinct profiles, their editorial introductions, and the active organization of special issues and debates. In the meantime, the journals

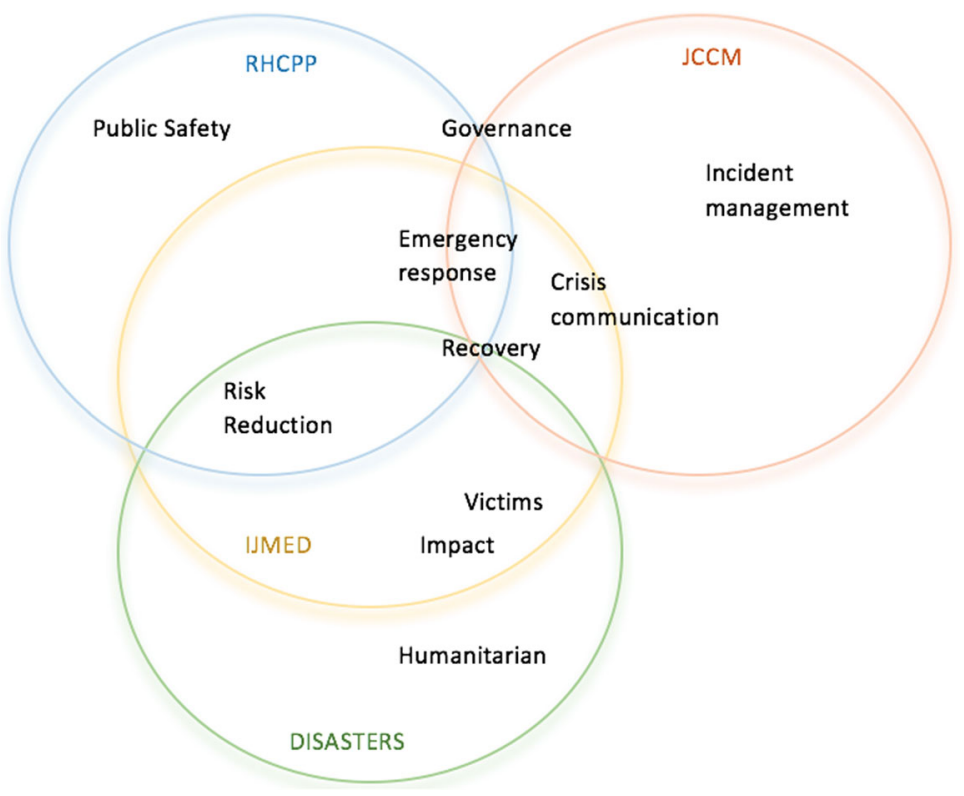

Figure 4. Topic Overlap Between Journals. 
enjoy machine-facilitated detection of individual contributions and similarities.

Sanneke Kuipers, Editor-in-chief RHCPP, Leiden University, Institute of Security and Global Affairs.

Jaroslaw Kantorowicz, Leiden University, Institute of Security and Global Affairs and Department of Economics.

Jan Mostert, Editorial assistant RHCPP, Leiden University, Institute of Security and Global Affairs.

\section{References}

Benoit, K., K. Watanabe, P. Nulty, A. Obeng, S. Müller, H. Wang, B. Lauderdale, and W. Lowe 2018. Quanteda: Quantitative analysis of textual data, R package, https://CRAN.R-project.org/package= quanteda

Blei, D. M., A. Y. Ng, and M. I. Jordan. 2003. "Latent Dirichlet Allocation." Journal of Machine Learning Research 3: 993-1022.

Boin, A., P. 't Hart, and S. Kuipers. 2017. "The Crisis Approach." In Handbook of Disaster Research, Handbooks of Sociology and Social Research, 2nd ed., ed. H. Rodríguez. New York, NY: Cambridge University Press, 23-38.

Gabrielatos, C. 2018. "Keyness Analysis: Nature, Metrics and Techniques." In Corpus Approaches to Discourse: A Critical Review, eds. C. Taylor, and A. Marchi. Oxford: Routledge, 225-58.

Kuipers, S., B. J. van Grieken, and M. B. A. van Asselt. 2018. "Risk, Hazards, and Crises in Research: What Risks Get Researched, Where, and How?" Risk, Hazards \& Crisis in Public Policy 9 (4): 384-96.

Kuipers, S., and N. H. Welsh. 2017. "Taxonomy of the Crisis and Disaster Literature: Themes and Types in 34 Years of Research." Risk, Hazards E Crisis in Public Policy 8 (4): 272-83.

Perry, R. W., and E. L. Quarantelli. 2005. What Is A Disaster? New Answers to Old Questions. Bloomington, IN: Xlibris Corporation.

Stallings, R. A. 2005. "Disaster, Crisis, Collective Stress and Mass Deprivation." In What Is A Disaster? New Answers to Old Questions, eds. R. W. Perry, and E. L. Quarantelli. Bloomington, IN: Xlibris Corporation, 237-74.

Turner, B. A., and N. F. Pidgeon. 1997. Man-Made Disasters, 2nd ed. Boston: Butterworth-Heinemann.

Van Wassenhove, L. N. 2006. "Humanitarian Aid Logistics: Supply Chain Management in High Gear." Journal of the Operational Research Society 57 (5): 475-89. 


\section{Appendix A: Methods Used for Data Collection and Analysis}

The primary method of analysis applied in this paper is an automated quantitative content (text) analysis performed on the corpus consisting of abstracts of four main journals identified in the crisis management literature (RHCPP, JCCM, IJMED, and Disasters). We followed the bag-of-words approach, whereby each abstract can be represented by a multiset of its words and where grammar and word order are disregarded. Prior to formal analysis, the corpus was preprocessed during tokenization. Standard pre-processing steps were as follows: lowercasing, performing stemming, removing stopwords, punctuations, and numbers. We also trimmed the document-feature matrix and kept only words that appear in at least in two documents and have at least two characters. Given the goal of the analysis, we have also decided to remove words, which had no capacity to discriminate between substantive topics (e.g., show, demonstrate, focus, approach, answer, etc.). The full list of removed tokens/features is available upon request. All preprocessing steps along with subsequent analyses were performed in $\mathrm{R} / \mathrm{R}$ Studio with the quanteda package (Benoit et al., 2018).

Three distinctive methods of automated text analysis were employed to capture journals' profiles. Our first inquiry was about the substantive topics that got published in these journals. To this end, we performed the LDA method (Blei et al., 2003). LDA is a type of unsupervised topic modeling technique that creates topics based on patterns of co-occurrence of words in the documents that are analyzed (here abstracts). There are two main parameters, which are at the discretion of the researcher when setting up the LDA topic model. These are a number of topics (the $k$ parameter) and the concentration of topics per document (the $\alpha$ parameter). Although there are some procedures (e.g., perplexity measure), which help the researcher to arrive at the optimal number of topics (k), it is recommended that the number of topics is derived based on substantive meaning rather than based on mathematical optimization. At the end, the task of the researcher is to interpret the latent dimensions of topics and thus parsimonious solutions may be preferred over fined-grained solutions, which result in many topics that are difficult to interpret. The most straightforward interpretation of topics was for $k=10$, thus the main analysis is performed for 10 topics, for which unambiguous labels could be found. Regarding the $\alpha$ parameter, we decided to set it to 0.5 , thus below the default value of $5\left(\alpha=\frac{50}{k}\right)$. This leads to a higher concentration of topics per document as compared to the default set-up. In the context of article abstracts, this choice is justified by the fact that typically a single article corresponds to one substantive topic. In other words, a journal article is rarely a mix of a large number of different substantive topics.

The second method employed in this article is a keyness analysis or a keyword analysis. This method is widely used in discourse analysis (see, for instance, Gabrielatos, 2018). The overarching idea behind the keyness analysis is to extract terms, which occur with unusual frequency in one corpus of texts as compared with another corpus. Transposing it to the context of this study, the keyness analysis boils down to searching for terms that occur with unusual frequency in the corpus of abstracts of one journal (corpus one) as compared to the expected frequency derived from the corpus of abstracts of all remaining journals (corpus two). We 
report only 10 key terms per journal, and these are the terms, which received the highest value of $\chi^{2}$ statistics).

Lastly, to further investigate the similarity of journal profiles, we applied several text similarity measures. The two most common text similarity metrics are Jaccard and cosine measures. The major difference between the two is that the latter takes into account the total length of the vectors while the former deals with a unique set of words. We think that in the context of abstract and journal level data, the cosine similarity is somewhat more relevant as the number of times a given word appears in a given corpus (e.g., "humanitarian") matters inasmuch as it gives an indication of importance and saliency of the particular issue. The Jaccard metrics discard the number of occurrences and look if particular words appear across examined corpuses. Hence, our primary choice for further analysis is the cosine similarity measure (the results based on the Jaccard metrics are available upon request). Once the similarity measures are computed, we convert these measures so they reflect the distances (dissimilarity $=1$-cosine similarity) and apply them in hierarchical cluster analysis. The similar results are obtained if we use a more standard metric as a text distance measure, such as for instance, the Kullback-Leibler distance.

We based the manual coding, in line with previous meta-reviews, on counting the frequency of key terms within the article titles of each journal in the selected period. We took the same list of codes we used in a previous mapping effort (Kuipers \& Welsh, 2017), to build on earlier findings. The selected periods are slightly different because we have included more recent years and started from 2010 onwards, which may explain slight differences in the results. The article titles of all four journals for the period 2010-2018 were searched for each crisis type (main codes and subcodes), and the articles were coded for the one particular crisis or disaster type identified as predominantly identified on the basis of title and abstract. If no particular type from the list could be identified, the category N/A (not applicable) applied. Once the collective bibliographies of all three journals had been searched for all key terms, these were collected into an aggregate count per year under one of the ten crisis types identified. Two coders conducted all coding manually. Coder reliability and results are discussed in the section "Reflection on topics vis-à-vis manual coding". First, we will discuss the results of the automated text analysis. 


\section{Appendix B: The Crisis Types Identified and Used by Manual Coding (cf. Kuipers \& Welsh, 2017)}

Armed conflict/hum. aid

Business

Climate/environment

Critical Infrastructure

Health

ICT/Cyber

Nature-induced disasters

Riots/Crowds

Terrorism

Toxic/pollution
War; international conflict; coup attempts; warfare; foreign policy crisis; conflicts; regimes; landmines; relief; aid; NGO; peace operations; consular emergency; armed conflict; [including reference to specific conflict sites and war zones: i.e., Somalia, Kosovo, Sudan, etc.]

Banking; business; corporate; business strategy; monetary crisis; financial crisis; firm; reputation; bankruptcy; small business; SME; boardroom; stakeholder; enterprise; suppliers; consumers; business; [including reference to specific brands and corporations, i.e., Enron, Bear Sterns, etc.]

Environmental emergencies; sustainable; environmental policy; climate; environmental agreements; drought; desertification; environment

Airport; high-risk industries; electricity sector; CIP; systemic approaches; public-private partnerships; systemic risks; plants; transportation systems; infrastructure

Medical emergency; plague; infectious diseases; food safety; epidemic; cholera; influenza; pandemic; veterinary diseases; health; [including reference to specific diseases or foods safety issues: BSE, SARS, Ebola, etc.]

Information technology; information systems; applications; computer; communications technology; systems evolution; innovations; data; sociotechnical disasters; cyberspace; Y2K; web; internet; ICT; cyber [including reference to specific incidents or malware: Stuxnet, notpetya, etc.]

Earthquake; flood; forest/bush fires; heatwave; wildfires; tsunami; hurricane; typhoon; disaster, [including reference to specific hurricanes, i.e., Katrina, Sandy]

Prison riots; stadium; unrest; mass event; violence; crowd; riot; hooligan, [including reference to specific incidents, i.e., Duisburg, Hillsborough]

Terror; jihad; kidnapping; hostage; anthrax; bombings; attack; terrorism [including reference to specific attacks, i.e., September 11]

Chemical industry; pipeline safety; toxic waste; nuclear power; oil spill; biological hazards; radioactive; biological agents; oil industry drilling; refineries; pollution; toxic, [including reference to specific spills, polluted sites or industries, i.e., Seveso, Bhopal, Deepwater Horizon] 